\section{BMJ Open} Ophthalmology

\title{
Birth weight and refractive state measured by Spot Vision Screener in children aged 40 months
}

\author{
Shunya Tatara (D , , ${ }^{1,2}$ Masako Ishii, ${ }^{1}$ Reiko Nogami ${ }^{3}$
}

To cite: Tatara S, Ishii M, Nogami R. Birth weight and refractive state measured by Spot Vision Screener in children aged 40 months. BMJ Open Ophthalmology 2021;6:e000808. doi:10.1136/ bmjophth-2021-000808

Received 22 May 2021 Accepted 8 November 2021
Check for updates

(c) Author(s) (or their employer(s)) 2021. Re-use permitted under CC BY-NC. No commercial re-use. See rights and permissions. Published by BMJ.

${ }^{1}$ Department of Orthoptics and Visual Sciences, Niigata University of Health and Welfare, Niigata, Japan

2Department of Vision Science, Kitasato University Graduate School of Medical Science, Sagamihara, Japan

${ }^{3}$ Division of Ophthalmology, Nogami Eye Clinic, Tsubame, Japan

Correspondence to Shunya Tatara; tatara@nuhw. ac.jp

\section{ABSTRACT}

Objectives Children with retinopathy of prematurity (ROP) often have myopia. Even without ROP, birth weight and refractive state are related immediately after birth, but this relationship is reduced with increasing age. Here, we examined whether refractive state and birth weight were associated in 40-month-old children.

Methods and analysis of 541 children aged 40 months in Tsubame City, Japan, who underwent a medical examination between April 2018 and March 2019, this cross-sectional study enrolled 411 whose birth weights were available ( $76 \%$ of all).

We measured the non-cycloplegic refraction using a Spot Vision Screener and correlated this with birth weight. Children were divided into three groups according to normal (2500-3500 g), high (>3500 g) or low (<2500 g) birth weights, and mean differences in spherical equivalent (SE) between the groups were analysed.

Results The average SE for the right eye was $0.34 \mathrm{D}$ (95\% Cl 0.28 to 0.40). Average birth weight was $3032.1 \mathrm{~g}$ (95\% Cl 2990.2 to 3073.9$)$. Birth weight did not correlate with SE for the right eye (Pearson's correlation, $r=-0.015$, $p=0.765$ ) or with the degree of anisometropia (Pearson's correlation, $r=-0.05, p=0.355)$. Furthermore, the mean SE showed no significant difference across the three groups of children with different birth weights (one-way analysis of variance, $p=0.939$ ).

Conclusion Data on refractive states and birth weight for 411 children of similar age in one Japanese city were analysed, showing that birth weight did not influence SE, $\mathrm{J0}, \mathrm{J} 45$ and the absolute degree of anisometropia at about 40 months of age.

\section{INTRODUCTION}

Ocular refraction is mostly based on corneal and ocular lens powers and axial lengths (ALs). A greater refraction of light by the cornea and/or crystalline lens yields myopia, and a weaker refraction yields hyperopia. Moreover, longer AL yields myopia, and a short AL yields hyperopia. As mentioned above, the mechanisms that determine ocular refraction are understood to some extent. ${ }^{1}$ However, the various causes of abnormal changes of corneal and/or lens powers and $\mathrm{AL}$ and their influences in regards to refractive error remain uncertain.

\section{Key messages}

What is already known about this subject?

Children with retinopathy of prematurity (ROP) often have myopia. Even in 1-week-old infants without ROP, birth weight and refractive state are associated as evidenced by the relationship between increasing myopia and decreasing birth weight. However, by about 7-9 years of age, birth weight and spherical equivalent (SE) are no longer related.

\section{What are the new findings?}

- It is thought that the relationship between birth weight and refraction becomes no longer apparent at some point after birth but before 6 years. Here, we investigated the relationship between refractive state in 40-month-old children and their birth weights and found that SE and the degree of anisometropia were not related to birth weight.

How might these results change the focus of research or clinical practice?

Although screening for refractive error based on birth weight is useful immediately after birth, our results suggest that this is not true in children who are 40 months old. Furthermore, refraction does not appear to be affected, even among low birth-weight infants, once children have reached the age of 40 months.

The AL is short in early childhood, yielding mild hyperopia in most children. ${ }^{2}$ The eyeball becomes larger with growth, usually yielding emmetropisation. ${ }^{3}$ Mild refractive errors and a small refraction difference between the two eyes are not associated with problems with visual performance. However, moderate to severe refractive errors and particularly large refraction differences between the two eyes are responsible for amblyopia. ${ }^{4}$ Amblyopia is difficult to detect at an early age, despite the importance of early treatment. ${ }^{5}$ Identifying risk factors for refractive errors would contribute to the prevention of amblyopia. This study investigated birth weight as one of the influential factors of refractive error in children.

Many individuals with retinopathy of prematurity (ROP) reportedly have myopia. ${ }^{6}$ 
The causes of myopia in ROP are the child's immaturity, severity of ROP disease and efficacy of ROP treatment, suggesting the possibility that size and weight at birth contribute to subsequent refractive error. However, the situation is unclear. $^{7}$ Excluding ROP, the relationship between birth weight and refractive error remains uncertain.

Varghese $e t a l^{8}$ reported that the cycloplegic spherical equivalent (SE) measured by retinoscopy was correlated with birth weight and gestational age in 599 infants 1 week of age. However, another study reported that in children aged 7-9 years, birth weight was not correlated with SE despite a greater birth weight being associated with longer AL. ${ }^{9}$ The reason for this was thought to be that emmetropisation results in compensatory changes in the ocular axial elongation primarily by changes in crystalline lens power. Mutti et $a l^{10}$ reported that the degree of hyperopia in infants decreases markedly after 6 months of age. We hypothesised that there would be a timepoint at which the relationship between birth weight and refraction would disappear and that this would occur between infancy and early childhood.

This study introduced the refraction test measured by Spot Vision Screener (SVS; Welch Allyn, New York) at the 3-year check-up implemented by the city, ${ }^{11}$ which allowed us to measure the refractive state of all children aged 40 months in Tsubame City, Niigata Prefecture, Japan. Therefore, this study aimed to correlate birth weight records kept by Tsubame City with refraction measured at the age of 40 months. SVS is based on the photorefraction method, ${ }^{12}$ which enables simultaneous measurement of refractive error in both eyes. SVS is characterised by a high measurable rate when estimated for children, and the success rate was reported to be $99.7 \%$ for 42-month-old children ${ }^{13}$ and 99.8 for 37 -month-old children. ${ }^{2}$ Regarding the measurement accuracy of SVS, the refractive values measured by SVS showed a moderate agreement with the results from cycloplegic retinoscopy refraction. ${ }^{14}$

\section{MATERIALS AND METHODS}

\section{Subjects}

This is a cross-sectional study involving 411 children in Tsubame City, Japan with records of birth weight from 541 children aged 40 months who underwent medical examination in Tsubame City from April 2018 to March 2019. A total of 130 children in Tsubame City, without birth weight record and recorded gestational age, were excluded. The main reason for lack of records was moving to Tsubame City. The information on children who were living in other local government areas at birth could not be obtained, for these children undergoing investigation at the age of 40 months.

\section{Methods}

Certified orthoptists were measured each refraction (spherical and, cylindrical power, cylinder axis and SE (spherical power+cylindrical power/2)) of the children using an SVS. The SE, J0 and J45 were used in all analyses for refraction. The $\mathrm{J} 0$ and $\mathrm{J} 45$ were calculated using the vector analysis of dioptric power according to the method of Thibos et $a l^{15}$ In addition to SE, S C A format (S; spherical power, $\mathrm{C}$; cylindrical power, $\mathrm{A}$; axis) compound refractive error is included. The birth weight and gestational age records kept by the city were correlated with the measured refractions. The numbers beyond the first decimal places of birth weight were truncated and gestational age was expressed in weeks (w) with the days truncated.

\section{Analysis}

SEs between the right and left eyes were compared using paired sample $t$ tests and one-way analysis of variance (one-way ANOVA). Children were allocated to one of three groups according to birth weight as follows: lowbirth weight group (birth weight $<2500 \mathrm{~g}$ ), normal birth weight group (birth weight 2500-3500 g) and high birth weight group (birth weight $>3500 \mathrm{~g}$ ). They were also separated into three groups according to gestational age as follows: premature group (gestational age $<37 \mathrm{w}$ ), fullterm group (gestational age 37-42 w) and postmature group (gestational age $>42 \mathrm{w}$ ). The SEs for each group are shown in table 1 as means and $95 \%$ CI. In addition to SE, S C A format compound refractive error is included for reference. Long's method ${ }^{16}$ was used to calculate the mean S C A format compound refractive error. We created 1000 bootstrapped samples with replacement to compute empirical SEs of the estimates and 95\% CIs. SEs, J0 and $\mathrm{J} 45$ of the right eye and degree of anisometropia were compared among the groups using one-way ANOVA. The degree of anisometropia was defined as the difference in SE between the two eyes when expressed as absolute values in the same way as by the method of Varghese $e t a l^{8}$

To check for multicollinearity, we correlated the birth weight with gestational age. Because the birth weight was correlated with gestational age, gestational age was excluded from further consideration. In later analysis, we correlated birth weight with the SE for the right eyes only. Moreover, we correlated birth weight with the absolute degree of anisometropia. Pearson's correlation analysis was used for the estimation of possible correlations.

Two-sided tests were used for statistical significance, and the significance level was set at a $p$ value $<0.05$. Statistical analysis was performed using EZR (Easy R) V.1.41 that is open-source software based on $\mathrm{R}$ and $\mathrm{R}$ commands. ${ }^{17}$

\section{Consent to participate}

The 40-month-old subjects of the study were clearly too young to provide consent, so permission was obtained from their parents or legal guardians.

\section{RESULTS}

This study investigated 411 children $(76.0 \%$ of 541 aged 40 months) in Tsubame City. None of the children had eye diseases, such as ROP. Table 1 separately lists results for the right and left eyes according to birth weight and 
Table 1 Individual refraction values for the right eyes categorised according to birth weights and gestational ages

\begin{tabular}{|c|c|c|c|c|c|c|c|c|}
\hline \multirow[b]{3}{*}{ Characteristic } & & \multirow[b]{3}{*}{ Number } & \multicolumn{3}{|c|}{ Spherical equivalent (D) } & \multicolumn{3}{|c|}{ SCA } \\
\hline & & & \multirow[b]{2}{*}{ Mean } & \multicolumn{2}{|c|}{$95 \% \mathrm{Cl}$} & \multirow[b]{2}{*}{ Mean } & \multicolumn{2}{|c|}{$95 \% \mathrm{Cl}$} \\
\hline & & & & LL & UL & & LL & UL \\
\hline \multirow[t]{2}{*}{ Total } & RE & 411 & 0.34 & 0.28 & 0.41 & $0.51-0.33178$ & $0.38-0.27174$ & $0.64-0.401$ \\
\hline & LE & 411 & 0.34 & 0.27 & 0.41 & $0.43-0.1710$ & $0.30-0.112$ & $0.55-0.2317$ \\
\hline \multicolumn{9}{|c|}{ Birth weight (g) } \\
\hline \multirow[t]{2}{*}{$<2500$} & $\mathrm{RE}$ & 36 & 0.30 & 0.03 & 0.57 & $0.51-0.433$ & $-0.09-0.16172$ & $1.06-0.7413$ \\
\hline & LE & 36 & 0.30 & 0.04 & 0.56 & $0.38-0.1712$ & $0.02-0.04155$ & $0.86-0.3858$ \\
\hline \multirow[t]{2}{*}{$2500-3500$} & RE & 321 & 0.34 & 0.27 & 0.43 & $0.51-0.32177$ & $0.35-0.24172$ & $0.66-0.401$ \\
\hline & LE & 321 & 0.35 & 0.28 & 0.42 & $0.43-0.189$ & $0.28-0.112$ & $0.59-0.2619$ \\
\hline \multirow[t]{2}{*}{$>3500$} & RE & 54 & 0.34 & 0.21 & 0.49 & $0.52-0.34177$ & $0.22-0.18163$ & $0.84-0.5211$ \\
\hline & LE & 54 & 0.38 & 0.23 & 0.52 & $0.41-0.0720$ & $0.20-0.02118$ & $0.70-0.2280$ \\
\hline \multicolumn{9}{|c|}{ Gestational age (weeks) } \\
\hline \multirow[t]{2}{*}{$<37$} & RE & 23 & 0.27 & -0.15 & 0.69 & $0.60-0.673$ & $-0.25-0.30174$ & $1.34-1.0711$ \\
\hline & LE & 23 & 0.13 & -0.32 & 0.58 & $0.40-0.533$ & $-0.45-0.24173$ & $1.10-0.8510$ \\
\hline \multirow[t]{2}{*}{$37-42$} & RE & 388 & 0.33 & 0.27 & 0.39 & $0.50-0.31176$ & $0.38-0.25172$ & $0.64-0.381$ \\
\hline & LE & 388 & 0.35 & 0.29 & 0.41 & $0.43-0.1511$ & $0.30-0.092$ & $0.56-0.2121$ \\
\hline$>43$ & - & 0 & & & & & & \\
\hline
\end{tabular}

Mean S C A, compound refractive error calculated via Long's equations (S, Spherical power; C, Cylindrical Power; A, Axis) LE, left eye; LL, lower limits; RE, right eye; UL, upper limits.

gestational age. The J0 (mean $\pm \mathrm{SD})$ for all subjects was $0.17 \pm 0.35 \mathrm{D}$ for the right eye and $0.08 \pm 0.33 \mathrm{D}$ for the left eye. The $\mathrm{J} 45($ mean $\pm \mathrm{SD})$ for all subjects was $-0.01 \pm 0.22 \mathrm{D}$ for the right eye and $0.03 \pm 0.21 \mathrm{D}$ for the left eye.

The SE $($ mean $\pm \mathrm{SD})$ was $0.34 \pm 0.66 \mathrm{D}$ for the right eye and $0.34 \pm 0.68 \mathrm{D}$ for the left eye, showing no significant difference (paired samples t test, $\mathrm{p}=0.949$ ). Since there was no significant difference in the SE between the left and right eyes, the subsequent statistical analysis was limited to the right eye. The birth weight $($ mean \pm SD) was $3032.1 \pm 431.8 \mathrm{~g}$. The gestational age $(\operatorname{mean} \pm \mathrm{SD})$ was $38.8 \pm 1.6 \mathrm{w}$. The birth weight was correlated with gestational age (Pearson's correlation, $\mathrm{r}=0.63, \mathrm{p}<0.001$ ), and birth weight and gestational age were multicollinear.

Mean S C A, compound refractive error calculated via Long's equations (S, spherical power; $\mathrm{C}$, cylindrical power; A, axis).

The Box-Whisker plots show SE, J0 and J45 for the right eyes classified by birth weight (figure 1 ). The $\mathrm{J} 0$ (mean $(95 \% \mathrm{CI})$ ) for the right eye was 0.21 (0.07 to 0.36$)$ $\mathrm{D}$ for the low birth weight group, 0.15 (0.11 to 0.19$) \mathrm{D}$ for the normal birth weight group and 0.17 (0.08 to 0.26) $\mathrm{D}$ for the high birth weight group. The J45 (mean (95\% CI) ) for the right eye was $0.03(-0.04$ to 0.10$) \mathrm{D}$ for the low birth weight group, $-0.02(-0.04$ to 0.00$) \mathrm{D}$ for the normal birth weight group and $-0.02(-0.01$ to 0.06$) \mathrm{D}$ for the high birth weight group. The absolute degree of anisometropia (mean $(95 \% \mathrm{CI})$ ), that is, the mean difference in SE across right and left eyes was 0.41 ( 0.18 to $0.64) \mathrm{D}$ for the normal birth weight group, 0.27 (0.23 to $0.31) \mathrm{D}$ for the high birth weight group and 0.22 ( 0.17 to
0.26) for the low-birth weight group (one-way ANOVA, $\mathrm{p}=0.182$ ). Thus, none of these comparisons was significant.

The birth weight was not correlated with $\mathrm{SE}$ at 40 months (Pearson's correlation analysis, $\mathrm{r}=-0.01, \mathrm{p}=0.765$; figure 2A). Birth weight was not correlated with the absolute degree of anisometropia (Pearson's correlation analysis, $\mathrm{r}=-0.05, \mathrm{p}=0.355$; figure $2 \mathrm{~B}$ ).

\section{DISCUSSION}

This study investigated 411 children $(76.0 \%$ of 541 aged 40 months) in Tsubame City, Japan and indicated that birth weight was not correlated with mean SE at 40 months. According to a previous study in Niigata, the average birth weight of children born in 1981-1988 was $3227-3264 \mathrm{~g}$ in boys and $3149-3188 \mathrm{~g}$ in girls. ${ }^{18}$ This study showed that the average birth weight of children born in Tsubame City, Niigata, from 2014 to 2015 , was $3032.1 \mathrm{~g}$. One possible explanation for this declining trend of birth weight is that the number of low-birth-weight infants has increased from the 1980s in Japan. ${ }^{19} 20$

The reason is increasing in the number of preterm deliveries and multiple gestations. ${ }^{20}$ Varghese $e t a l^{8}$ reported that $\mathrm{SE}$ is correlated with birth weight and with gestational age in 1-week-old infants. Saw et at analysed the correlation between birth weight and refraction in children aged 7-9 years and found that birth weight was not correlated with SE despite heavier birth weight being associated with longer AL. They posited that a possible explanation for this finding was the observed compensatory flattening of the cornea, resulting in 

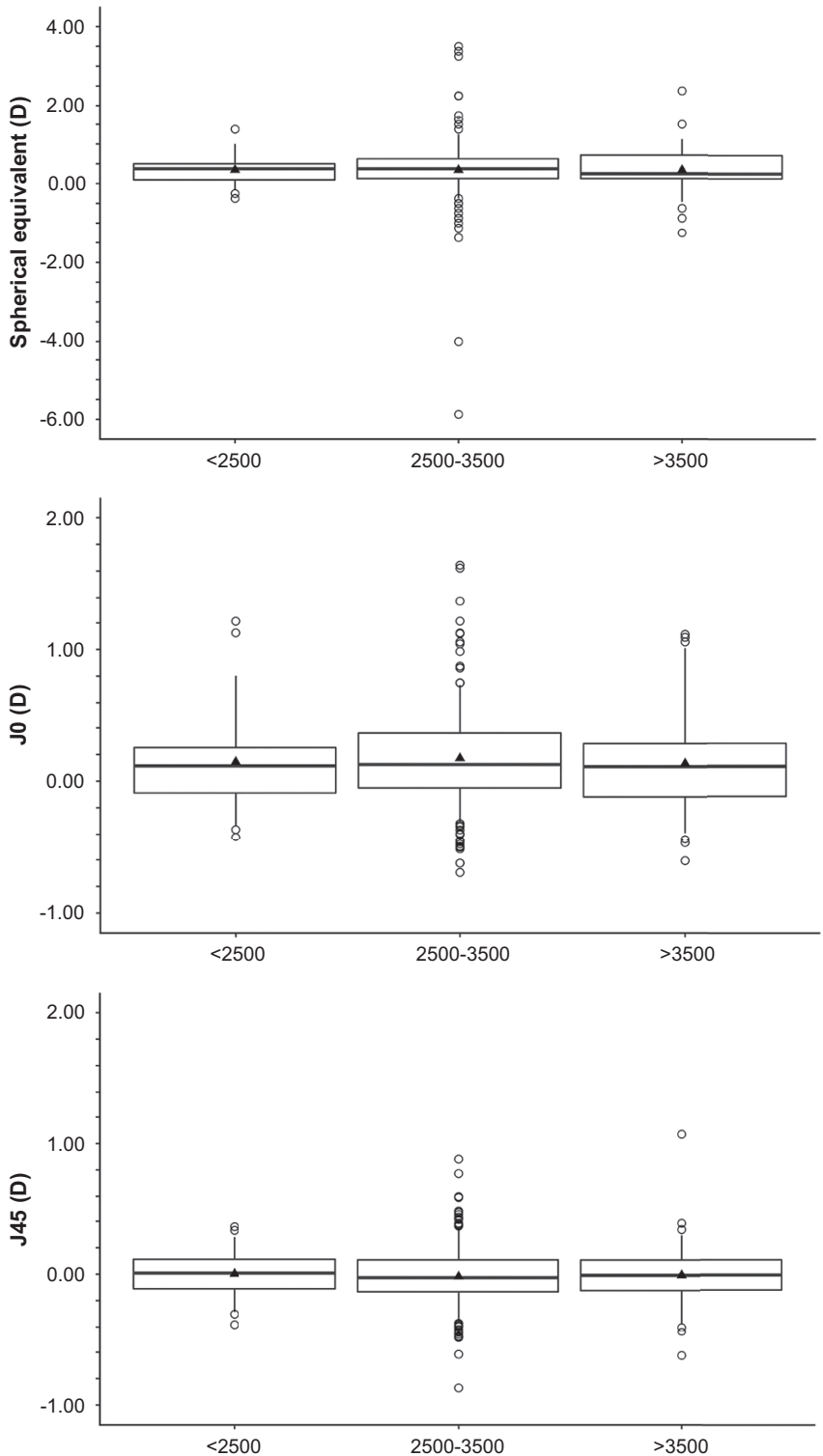

Figure 1 Refractive states for the right eyes classified by birth weight. The spherical equivalent (SE), J0, J45 are shown in three groups: the normal (2500-3500 g), high $(>3500 \mathrm{~g})$ and low $(<2500 \mathrm{~g})$ birth weight groups. The boxes show the 25th to 75th percentiles, the whiskers show the 5th to 95th percentiles, the horizontal lines show the median and the plots inside box indicate the average value. The normal (2500-3500 g), high (>3500 g) and low (<2500 g) birth weight groups were not a significant difference in SE (one-way ANOVA, $p=0.939$ ), J0 (one-way ANOVA, $p=0.673$ ), J45 (oneway ANOVA, $p=0.522$ ) for the right eyes. ANOVA, analysis of variance.

decreased power. Such compensatory change in corneal power works against elongation of AL, mostly leading to emmetropisation. ${ }^{21}$ The development of most ocular optical components and refractive error could be described from infancy through early childhood by functions combining exponential and quadratic forms. ${ }^{10}$

We predicted that gestational age and birth weight would be related to SE immediately after birth, but that these would not be related to refraction as the infant aged up. Therefore, we evaluated the correlation between birth weight and refraction in children aged 40 months. This age is lower than that used in the study by Saw et af and we found that birth weight was not correlated with mean SE in children aged 40 months. Children aged 7-9 years who were heavier or had a higher BMI tended to have more hyperopic refractions. ${ }^{22}$ It appears that while refraction in a child's eye is affected by birth weight and by gestational age immediately after birth, as the child grows up, only the current weight of the child perhaps affects SE since we have shown that birth weight and gestational age are not related to refraction at 40 months of age. Mutti et $a l^{10}$ reported that $\mathrm{SE}$ was $+2.16 \mathrm{D}$ at 3 months and changed to $+1.36 \mathrm{D}$ at 9 months. Cook et $a l^{23}$ reported that in a study of premature infants without ROP, SE was $-2.00 \mathrm{D}$ at 30 weeks and changed to +2.12 $\mathrm{D}$ at 60 weeks of age. Therefore, infants exhibit rapid changes of the refractive states in the first few months of life after premature birth. Although it has been reported that there was a significant difference in astigmatism, and anisometropia between full-term and preterm infants without ROP by 6 months of age, ${ }^{24}$ in our study, the astigmatism and anisometropia were not related at 40 months of age. The reason for this is thought to be that the refractive error and most ocular components displayed an early exponential phase of rapid development during the first 1-2 years of life. ${ }^{10}$ Varghese $e t a l^{8}$ reported that the use of birth weight as a screening tool for refraction in newborn babies is useful, but our study revealed that birth weight cannot be used to predict SE at 40 months of age.

The causes of refractive error include both genetic and environmental factors. Children whose parents have myopia tend to also develop myopia. ${ }^{25}$ A genome-wide association study reported the existence of genes with potential relationship with myopia. ${ }^{26}$ Regarding environmental factors, shorter distances for close work, more time spent reading and near-oriented activities with less time outdoors are reportedly related to myopia. ${ }^{25}$ However, the possible influences of other environmental factors, such as birth weight ${ }^{8927}$ and parents' smoking, ${ }^{2829}$ remain unclear. The present study revealed that birth weight did not correlate with the SE of the child at the age of 40 months.

This study has some limitations and due to the singlecentre design, some sampling bias may be present. Also, due to issues with multicollinearity (birth weight correlating with gestational age), an additional multivariate analysis was not practical. Further detailed explorations, including longitudinal studies from birth onwards, of the causes of refractive error are warranted. The study was conducted based on the measurements recorded during routine examinations implemented by Tsubame City, which allowed us to measure parameters in children aged 40 months in one city in Japan and obtain epidemiologically valid data. However, being a city medical check-up, there were restrictions on the variables that we were allowed to measure. Therefore, we could not measure AL, corneal radii or cycloplegic 
A)

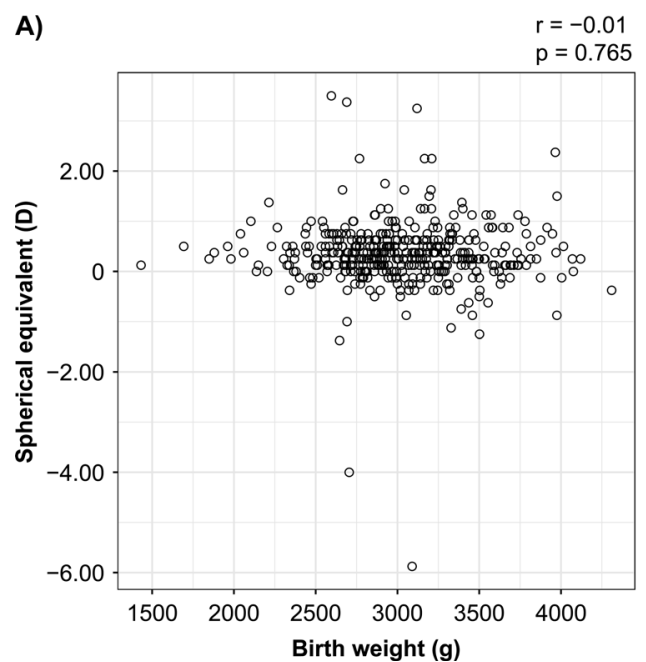

B)

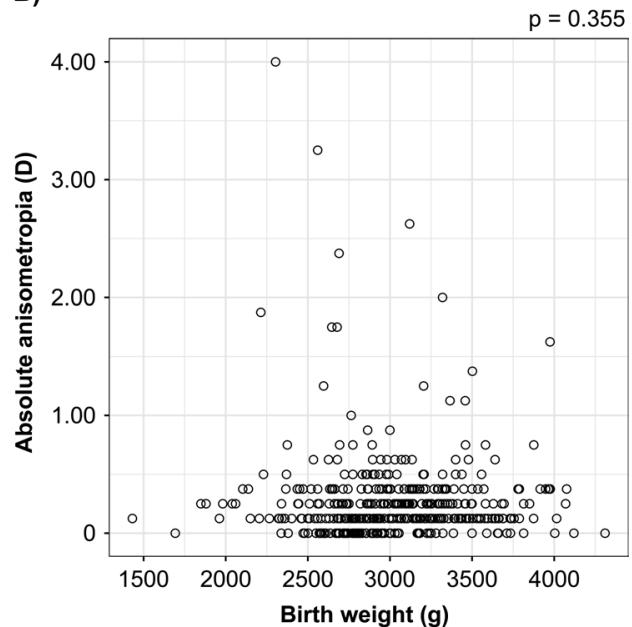

Figure 2 Correlation between birth weight and refraction The ordinate denotes birth weight $(\mathrm{g})$, and abscissa represents refraction (D) of the child at the age of 40 months. (A) Relationship between SE of the right eyes and birth weights; there was no correlation (Pearson's correlation analysis, $r=-0.01, p=0.765$ ). (B) Relationship between absolute refraction difference in SE between the right and left eyes and corresponding birth weights; there was no correlation (Pearson's correlation analysis, $r=-0.05, p=0.355)$.

refractions. Typically, cycloplegic refractions are used in children; however, we used the SVS to measure noncycloplegic refractions. As SVS can measure refractions at a distance of $1 \mathrm{~m}$ between the patient and the infrared target, it has been reported that SVS has significantly less accommodation activation than other refraction testing equipment and that nearly true refractive state can be detected without the use of cycloplegia. ${ }^{30} \mathrm{Mu}$ et al reported that ${ }^{14}$ the refractive values measured from SVS showed a moderate agreement with the results from cycloplegic retinoscopy refraction that is the gold standard to measure refractive state in children. However, it has been pointed out that SVS, which measures refractive error by the photorefraction method, may have an inaccurate cylindrical power when the device or the subject's face is tilted. ${ }^{30}$ In this study, when comparing the cylindrical powers of the right and left eyes, the cylindrical powers of the left eye tended to be lower. There was no obvious reason for this difference in cylindrical power between the right and left eyes in these subjects. Therefore, it is possible that the intrinsic principle of SVS measurement is the reason for this. In addition, the axis of cylindrical power for the left eye, which was classified by birth weight, tended to be variable. From these findings, a cautionary note might be that the evaluation of the cylindrical power measured by SVS needs to be considered in future.

Acknowledgements The authors would like to thank Tsubame City Health Promotion Division and the staff for their cooperation.

Contributors Contributors ST is the first author collected and analysed the data and wrote the manuscript. MI collected and interpreted the data. RN revised the manuscript critically for important intellectual content. All authors read and approved the final manuscript.

Funding This work was supported by JSPS KAKENHI Grant Number JP19K14184. The funders played no role in the design or conduct of the study, nor in the decision to submit the manuscript for publication.
Competing interests None declared.

Patient and public involvement Patients and/or the public were not involved in the design, or conduct, or reporting, or dissemination plans of this research.

Patient consent for publication Not applicable.

Ethics approval The research protocol adhered to the guidelines of the Declaration of Helsinki. This study was approved by the Ethics Committee of Niigata University of Health and Welfare (18010-180629). The Ethics Committee approved the placement of a poster fully explaining the purpose and content of this study in the investigation hall as an alternative to informed consent. Since the participants of the present study were too young, their parents or legal guardians verbally approved this study.

Provenance and peer review Not commissioned; externally peer reviewed.

Data availability statement Data are available upon reasonable request. Not applicable.

Open access This is an open access article distributed in accordance with the Creative Commons Attribution Non Commercial (CC BY-NC 4.0) license, which permits others to distribute, remix, adapt, build upon this work non-commercially, and license their derivative works on different terms, provided the original work is properly cited, appropriate credit is given, any changes made indicated, and the use is non-commercial. See: http://creativecommons.org/licenses/by-nc/4.0/.

ORCID iD

Shunya Tatara http://orcid.org/0000-0002-6569-1370

\section{REFERENCES}

1 Iribarren R. Crystalline lens and refractive development. Prog Retin Eye Res 2015;47:86-106.

2 Tatara S, Maeda F, Mizuno N, et al. Refraction and pupil diameter in 3-year- and 1-month-old children as measured by spot vision Screener. Sci Rep 2019;9:15622.

3 Ingram RM, Barr A. Changes in refraction between the ages of 1 and 3 1/2 years. Br J Ophthalmol 1979;63:339-42.

4 DeSantis D. Amblyopia. Pediatr Clin North Am 2014;61:505-18.

5 Pediatric Eye Disease Investigator Group.. A randomized trial of atropine vs. patching for treatment of moderate amblyopia in children. Arch Ophthalmol 2002;120:268-78.

6 Baker PS, Tasman W. Myopia in adults with retinopathy of prematurity. Am J Ophthalmol 2008;145:1090-4.

7 Mao J, Lao J, Liu C, et al. Factors that influence refractive changes in the first year of myopia development in premature infants. $J$ Ophthalmol 2019;2019:1-6.

8 Varghese RM, Sreenivas V, Puliyel JM, et al. Refractive status at birth: its relation to newborn physical parameters at birth and gestational age. PLoS One 2009;4:e0004469. 
9 Saw S-M, Tong L, Chia K-S, et al. The relation between birth size and the results of refractive error and biometry measurements in children. Br J Ophthalmol 2004;88:538-42.

10 Mutti DO, Sinnott LT, Lynn Mitchell G, et al. Ocular component development during infancy and early childhood. Optom Vis Sci 2018;95:976-85.

11 Ishii M, Tatara S, Ubukata H. Vision examination for 3-year-old children in Tsubame City: transition of the health checkup program and accuracy of the screening test. Niigata $J$ Health Welfare 2019;19:57-66 https://ci.nii.ac.jp/naid/120006791457/

12 Howland HC, Howland B. Photorefraction: a technique for study of refractive state at a distance. J Opt Soc Am 1974;64:240-9.

13 Hayashi S, Suzuki I, Inamura A, et al. Effectiveness of the spot vision screener in screening 3-year-old children with potential amblyopia in Japan. Jpn J Ophthalmol 2021;65:537-45.

$14 \mathrm{Mu} \mathrm{Y,} \mathrm{Bi} \mathrm{H,} \mathrm{Ekure} \mathrm{E,} \mathrm{et} \mathrm{al.} \mathrm{Performance} \mathrm{of} \mathrm{spot} \mathrm{photoscreener} \mathrm{in}$ detecting amblyopia risk factors in Chinese pre-school and school age children attending an eye clinic. PLoS One 2016;11:e0149561.

15 Thibos LN, Wheeler W, Horner D. Power vectors: an application of fourier analysis to the description and statistical analysis of refractive error. Optom Vis Sci 1997;74:367-75.

16 Long WF. A matrix formalism for decentration problems. Am J Optom Physiol Opt 1976;53:27-33.

17 Kanda Y. Investigation of the freely available easy-to-use software 'EZR' for medical statistics. Bone Marrow Transplant 2013;48:452-8.

18 Doi T, Kahyo H, Sone T, et al. Secular changes of the mean birth weight in Japan during the past 20 years (single births, 1969-88). Jpn. J. Hyg. 1993;47:1058-72.

19 Morisaki N, Urayama KY, Yoshii K, et al. Ecological analysis of secular trends in low birth weight births and adult height in Japan. $J$ Epidemiol Community Health 2017:71:1014-8.
20 Takimoto H, Yokoyama T, Yoshiike N, et al. Increase in low-birthweight infants in Japan and associated risk factors, 1980-2000. J Obstet Gynaecol Res 2005;31:314-22.

21 Gordon RA, Donzis PB. Refractive development of the human eye. Arch Ophthalmol 1985;103:785-9.

22 Saw S-M, Chua W-H, Hong C-Y, et al. Height and its relationship to refraction and biometry parameters in Singapore Chinese children. Invest Ophthalmol Vis Sci 2002;43:1408-13.

23 Cook A, White S, Batterbury M, et al. Ocular growth and refractive error development in premature infants without retinopathy of prematurity. Invest Ophthalmol Vis Sci 2003;44:953-60.

24 Uprety S, Morjaria P, Shrestha JB, et al. Refractive status in Nepalese pre-term and full-term infants early in life. Optom Vis Sci 2017:94:957-64.

25 Ip JM, Saw S-M, Rose KA, et al. Role of near work in myopia: findings in a sample of Australian school children. Invest Ophthalmol Vis Sci 2008;49:2903-10.

26 Solouki AM, Verhoeven VJM, van Duijn CM, et al. A genome-wide association study identifies a susceptibility locus for refractive errors and myopia at 15q14. Nat Genet 2010;42:897-901.

27 Ojaimi E, Robaei D, Rochtchina E, et al. Impact of birth parameters on eye size in a population-based study of 6-year-old Australian children. Am J Ophthalmol 2005;140:535.e1-535.e.

28 Saw S-M, Chia K-S, Lindstrom JM, et al. Childhood myopia and parental smoking. Br J Ophthalmol 2004;88:934-7.

29 Iyer JV, Low WCJ, Dirani M, et al. Parental smoking and childhood refractive error: the stars study. Eye 2012;26:1324-8.

30 Hayashi S, Edamatsu H, Numakura C. Evaluation of the spot vision screener in young children in Japan [in Japanese]. Folia Jpn de Ophthalmol Clin 2017:10:399-404. 